Escuela de Ciencias Sociales y Humanidades, UNED, Costa Rica https://revistas.uned.ac.cr/index.php/espiga ISSN: 1409-4002 • e-ISSN: 2215-454X

\title{
El humanismo latinoamericano y caribeño de la segunda mitad del siglo XX
}

\section{Latin American and Caribbean Humanism from the Second Half of the Twentieth Century}

\section{L’Humanisme Latino-Américain et des Caraïbes de la deuxième moitié du XXème siècle}

Walter Calvo-Gómez *

https://orcid.org/0000-0003-3697-1215

Recibido: 8 de marzo de 2021 • Aceptado: 9 de abril de 2021

* Bachillerato en Historia, Universidad Nacional (UNA), de Costa Rica. Licenciatura en Docencia en Historia, Universidad Estatal a Distancia, de Costa Rica. Maestría en Ciencias de la Educación con énfasis en Docencia, Universidad Americana, de Costa Rica. Egresado de la Maestría en Humanismo, Sociedad y Ambiente, Centro de Estudios Generales (CEG-UNA). Académico de Historia de la Cultura de la Universidad Técnica Nacional, de Costa Rica. Correo: wcalvo@utn.ac.cr 


\section{Resumen}

Este artículo reafirma la existencia de un humanismo latinoamericano y del Caribe mediante un acercamiento teórico-historiográfico. Realiza un análisis hermenéutico de estudios en el ámbito de la historia de las ideas y del pensamiento crítico-filosófico de América Latina y del Caribe. Para esto, se eligió una metodología orientada a los siguientes tópicos: primero, manifestar el robustecimiento del pensamiento crítico-filosófico latinoamericano en el siglo $\mathrm{XX}$ con las contribuciones de estudios que contextualizan las realidades históricas e identitarias de los pueblos latinoamericanos y caribeños; segundo, destacar la relevancia del humanismo latinoamericano como visión histórica-universal; tercero, realizar una revisión crítica y concisa que pretende evidenciar y cohesionar el pensamiento crítico-filosóficoliterario con la praxis de fin del siglo XIX con José Martí e inicios del XX con Enrique Rodó, y con las aportaciones del pensamiento marxista de Mariátegui; cuarto, analizar el humanismo latinoamericano y caribeño en la segunda mitad del siglo veinte, mediante la identificación y aportes de algunos de los principales representantes.

Palabras clave: Colonialidad, historicidad, Nuestra América, pensamiento latinoamericano.

\section{Abstract}

This article reaffirms the existence of a Latin American and Caribbean humanism through a theoretical-historiographical approach. It carries out a hermeneutic analysis of studies in the field of Latin American and Caribbean history and critical-philosophical thinking. For this, a methodology oriented to the following topics was chosen: first, to manifest the strengthening of Latin American critical-philosophical thinking in the twentieth century with the contributions of studies that contextualize the historical and identity realities of the Latin American and Caribbean peoples; second, to highlight the relevance of Latin American humanism as a historical-universal vision; third, to carry out a critical and concise review that aims to demonstrate and unite critical-philosophical-literary thinking with the praxis of the late nineteenth century with José Martí and the beginning of the twentieth with Enrique Rodó, and with the contributions of the Marxist thought of Mariátegui; fourth, to analyze Latin American and Caribbean humanism in the second half of the twentieth century, through the identification and contributions of some of its main representatives.

Keywords: Coloniality, historicity, Latin American thought, Our America.

\section{Résumé}

Cet article réaffirme l'existence d'un humanisme Latino-Américain et des Caraïbes à travers d'une approche théorique et historiographique ainsi que d'une analyse herméneutique des études dans le domaine de I'histoire des idées et de la pensée critique-philosophique de l'Amérique Latine et du Caraïbe. Pour cela, on a choisi une méthodologie orientée aux sujets suivants: d'abord, démontrer l'affermissement de la pensée critique et philosophique latinoaméricaine dans le XXème siècle grâce aux contributions des études qui mettent en contexte les réalités historiques et identitaires des peuples latinoaméricains et des Caraïbes. Ensuite, mettre en valeur l'importance de l'humanisme latinoaméricain comme vision historiqueuniverselle. Puis, faire une révision critique et concise pour mettre en évidence et en cohésion la pensée critique-philosophique-littéraire avec la pratique de la fin du XIXème siècle de José Martí et du début du XXème s. d'Enrique Rodó, ainsi qu'avec les apports de la pensée marxiste de Mariátegui. Finalement, analyser I'humanisme latinoaméricain et du Caraïbe dans la deuxième moitié du XXème s. moyennant l'identification et les apports des certains des principaux représentants.

Mots-clés: Colonialité, historicité, Notre Amérique, pensé latinoaméricaine. 


\section{Introducción}

En términos generales, el tema del humanismo ha estado presente en los debates del pensamiento de América Latina y el Caribe. Por esto, el presente artículo incursiona en el ámbito del humanismo latinoamericano, como parte inherente del pensamiento crítico-filosófico, que ha configurado nuevas e innovadoras corrientes de reflexión y de ideas que profundizan en la investigación de sus realidades históricas, políticas y culturales. Lo que justifica repensar el humanismo como categoría discursiva, así como proyecto de carácter intelectual, ideológico, ético-filosófico y social que ha permitido identificarlo en su diversidad conceptual y contextualmente.

Al referirse a los principios humanistas, se parte de la autenticidad del pensamiento crítico en Nuestra América. En otras palabras, resaltar los principales postulados que conlleven a un pensamiento alejado de las posiciones eurocentradas absolutas, como lo plantea Guadarrama ${ }^{1}$, «en el pensamiento latinoamericano se distingue que prevalece una clara tendencia de confianza en las potencialidades cognoscitivas y desalienadoras del hombre, de evasión del escepticismo y de cultivo de las ideas y la praxis humanista». Partiendo de lo expresado por Guadarrama, se observa la existencia de un discurso y una praxis en las argumentaciones de este trabajo, lo que permite pensar que su génesis se gesta a partir del siglo XIX con las acciones emancipadoras martianas en tierras antillanas.

Para cumplir con los objetivos, se siguió una metodología que, en primer lugar, requería una reseña histórica del humanismo en su pluralidad, así como ubicar el espacio-tiempo en que actúan algunos de los principales representantes humanistas de Nuestra América para mediados del siglo XX y sus aportes, que robustecieron las ideas que modelan el pensamiento crítico-filosófico hasta la actualidad. Aunado a los dos aspectos anteriores, se rescatan los principios humanistas que forjan la Filosofía de la Liberación, la Teología de la Liberación, la Pedagogía del Oprimido, que exhiben como postulados comunes buscar la dignidad y la equidad del ser humano.

Se da una lectura a los principales representantes humanistas cuyos aportes han esclarecido una realidad latinoamericana que viene caminando junto a la dominación de la colonialidad, como espacio de alienación, desde el momento en que el primer europeo puso pie en el continente con fines de despotismo económico, político y cultural. Se analizan los discursos de décadas pasadas los cuales claman por la necesidad de erigir un pensamiento liberador que permita finalizar con el posicionamiento enajenado en el actuar ciudadano de Latinoamérica.

\footnotetext{
1 Pablo Guadarrama González, «Humanismo y autenticidad cultural en el pensamiento latinoamericano», Anales del Seminario de Historia de la Filosofía 21 (2004): 170, acceso: 19 de noviembre de 2020, https:// dialnet.unirioja.es/servlet/articulo?codigo $=989377$
} 


\section{El humanismo latinoamericano}

se ha venido preocupando por el reconocimiento de todo ser humano en la dignificación del ser, reconociendo también la creación cultural como posibilidades de existencia, en este sentido cualquiera de las diferentes formas de existencia. El humanismo latinoamericano, entonces, parte de un reconocimiento del otro desde su diferencia y de las diversas culturas en relación proporcional. $^{2}$

En el siglo XX se construye un pensamiento crítico-filosófico, dando pie a la Filosofía de la Liberación, la Teología de la Liberación y la Pedagogía del Oprimido. La Filosofía de la Liberación nace como producto de un trabajo colectivo de reconocidos intelectuales latinoamericanos en la década de 1970. Este colectivo estuvo integrado por Osvaldo Adelmo Ardiles, Mario Casalla, Horacio Cerruti Guldberg, Carlos Cullen, Enrique Dussel, Rodolfo Kusch, Arturo Andrés Roig, Juan Carlos Scannone y Julio de Zan. En palabras de Scannone, la Filosofía de la Liberación nacía:

influida entonces por la teoría de la dependencia, que se estaba propagando en las ciencias sociales latinoamericanas (Faleto y Cardoso; Falls Borda, G. Frank y otros). [Pero nacía también] a modo de Manifiesto, que ese filosofar no parte del ego (yo pienso, yo trabajo, yo conquisto...), sino desde los pobres y oprimidos, y la praxis de liberación, tomando en serio los condicionamientos epistemológicos y políticos del pensar mismo. ${ }^{3}$

Se trata de un pensamiento crítico-filosófico de una nueva generación en busca de la transformación social y que se constituye en un instrumento de liberación contra las profundas desigualdades a las cuales han sido sometidos los pueblos latinoamericanos y caribeños desde el periodo de la Conquista, por ello la Filosofía de la Liberación posee un alto contenido de humanismo.

De manera paralela, irrumpe la Teología de la Liberación con un pensamiento crítico sobre la situación de pobreza, de miseria y de pocas oportunidades que comparten los pueblos latinoamericanos. En 1971, Gustavo Gutiérrez publica su libro: Teología de la liberación. Perspectivas, así como Hugo Assmann, quien publica Opresión-liberación: desafío a los cristianos, reafirmando tanto a la Filosofía y a la Teología de la Liberación como proyectos emancipadores al ratificar discursivamente su compromiso con los pueblos dominados de América Latina.

Por otro lado, surge la posibilidad de relacionar los aportes del humanismo en América Latina en el ámbito educativo con el surgimiento de la Pedagogía del

\footnotetext{
2 Diana Marcela Gómez Sánchez, Juan Guillermo Delgado Martínez y Néstor Iván Mejía Hincapié, «Aportes del pensamiento latinoamericano a la comprensión de la relación entre los conceptos de universidad, humanismo y sociedad», Revista Latinoamericana de Estudios Educativos 11, n. 2 (2015): 80, acceso: 20 de noviembre de 2020, https://www.redalyc.org/articulo.oa?id=134146842004

3 Juan Carlos Scannone, «La filosofía de la liberación: historia, características, vigencia actual», Teología y vida 50, n. ${ }^{\circ} 1-2$ (2009): 60-61, acceso: 27 de noviembre de 2020, https://scielo.conicyt.cl/pdf/tv/v50n1-2/ art06.pdf
} 
Oprimido, propuesta por el brasileño Paulo Freire. En palabras de Beorlegui ${ }^{4}$, «el modo pedagógico para acompañar al pueblo en la superación de su dependencia, en la medida en que él mismo tiene que hacerse sujeto de su propia liberación». Las dos obras fundamentales de Freire son: Educación para la praxis de la libertad y Pedagogía del oprimido, en donde sostiene «que la educación es un proceso de concientización más que de mera transmisión de saberes, lo que daría una línea viva en hoy en día: la educación popular» ${ }^{5}$. Estas tres corrientes del pensamiento crítico-filosófico en el contexto latinoamericano impulsaban los principios sobre un profundo humanismo desde la perspectiva del principio-liberación como emancipación integral y auténtica.

\section{Antecedentes}

El siglo XX fue testigo de un valioso auge del pensamiento crítico latinoamericano, el cual se dio a la tarea de reinterpretar lo particular de la historia de Nuestra América y que invita a una praxis que lleve a las acciones transformadoras socioculturales, basada en una elaboración teórica apegada a las realidades históricas e identitarias de los pueblos latinoamericanos y caribeños. El pensamiento crítico latinoamericano propone alternativas sistémicas a los contextos del siglo pasado y a los actuales marcados por las inequidades, discriminaciones y opresiones que afectan a las mayorías de las colectividades americanistas. Por consiguiente, se plantea una plataforma teórico-práctica para la construcción de democracias reales, auténticas, que reflejen la equidad, la alteridad y la convivencia humanas. Esto por cuanto «la esencia del hombre es social y la esencia de la sociedad es la praxis: abstraída de la praxis, la teoría solo puede atascarse en el misticismo y la mistificación», como lo indicaba Henri Lefebvre» ${ }^{6}$. De manera tal, que se constituya en la búsqueda de un futuro deseable y justo donde los grupos oprimidos o las colectividades no tomadas en cuenta se constituyan en sujetos de la historia.

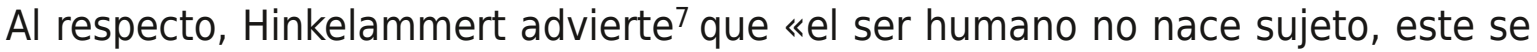
construye con otros y resistiendo a quienes no le permiten constituirse como tales. Es importante remarcar que la actividad colectiva es la que permitirá la constitución de sujetos»; así, se identifica el sujeto como elemento activo del rol protagónico, que como actor social debe tomar al partir del ámbito de la praxis para contribuir al rescate y reafirmación de la dignidad e identidad desde lo individual y lo colectivo. Se trata entonces de reafirmar lo humano como la

\footnotetext{
4 Carlos Beorlegui, Historia del pensamiento filosófico latinoamericano. Una búsqueda incesante de la identidad (Bilbao: Publicaciones de la Universidad de Deusto, 2010): 681, acceso: 25 de noviembre de 2020, https://filosofiaum.files.wordpress.com/2014/06/beorlegui.pdf

5 Roberto Fernández Retamar, Pensamiento de nuestra América. Autorreflexiones y propuestas (Buenos Aires: CLACSO, 2006): 69, acceso: 2 de diciembre de 2020, http://bibliotecavirtual.clacso.org.ar/clacso/ formacion-virtual/20100721121022/retamar.pdf

6 Mario Magallón Anaya, «Filosofía y pensamiento crítico latinoamericano de la actualidad», de Raíz Diversa 1, n. ${ }^{\circ} 1$ (2014): 48, acceso: 5 de diciembre de 2020, http://biblioteca.clacso.edu.ar/Mexico/ppel-unam/ 20160614015135/Magallon.pdf

7 Héctor Altamirano Martínez, «Notas sobre el pensamiento crítico latinoamericano y la construcción de democracias liberadora», Temas de Nuestra América 34, 63 (2018): 43, acceso:19 de diciembre de 2020.
} 
máxima expresión del respeto a los derechos inalienables que deben disfrutar el conjunto de ciudadanos de la sociedad.

Baraona ${ }^{8}$, por su parte, aporta elementos para reafirmar lo anterior:

la humanidad es humanidad a través de la praxis histórica que le permite definirse en cuanto tal en cada etapa de nuestra evolución social y teniendo siempre un horizonte ideológico que define ciertos rasgos de nuestra naturaleza como más deseables que otros. [...] Hoy esa desiderata que define el horizonte del humanismo más avanzado, que hemos denominado como «humanismo integral», supone una estrategia espiritual, política e intelectual, que defina un ser humano altruista, libertario, solidario, e igualitario, que sea la fuente y la meta de todo valor, y que de ello se genere la defensa de la dignidad y libertad esenciales de todos los seres humanos y la afirmación del carácter autoemancipatorio de nuestra praxis como especie.

Este estudio procura el fortalecimiento y reinvención de un humanismo enraizado en la cultura autóctona y en el sentir latinoamericano. La edificación de este pensamiento crítico-filosófico se ha cimentado en una reflexión epistémica como condición propia e implícita desde la visión de la filosofía, consecuente con la realidad sociohistórica de América Latina y el Caribe para la ejecución de las transformaciones estructurales, que permitan la construcción de sociedades más inclusivas. Sin embargo, la arquitectura de un pensamiento crítico-filosófico (contrario a las posiciones eurocentradas) debe tener características especiales que incorpore los elementos anclados en nuestra cultura originaria latinoamericana y del Caribe.

De esta manera, los aportes teóricos (no exentos de la praxis) que se plantean durante el siglo XX están marcados y enmarcados bajo una lectura en un contexto socio-histórico, socio-político y socio-cultural, que rescata las cosmogonías autóctonas y que reivindica una nueva lectura de un humanismo con idiosincrasia propia de Abya Yala, creando un rechazo a toda influencia de carácter hegemónico foráneo, sobre todo eurocéntrico. Guadarrama en este sentido destaca que

La reivindicación del humanismo en general presupone incluir necesariamente la forma particular que este ha adoptado en el desarrollo del pensamiento en América Latina y cómo se ha revelado de manera singular en cada intelectual auténtico de esta región. Esto contribuye a superar el escollo del enfoque eurocentrista que ha subestimado los valores del pensamiento latinoamericano y en especial de su producción filosófica. ${ }^{9}$

Las ciencias sociales o humanas -ciencias de la realidad humana- permiten abrir espacios que facilitan la investigación historiografía en el análisis de la

8 Miguel Baraona Cockerell, Diez ensayos críticos (San José: Editorial Germinal, 2011), 345.

9 Guadarrama, Humanismo y autenticidad cultural...,170. 
edficación de la cultura de los pueblos originarios y el estudio del periodo histórico posterior que se inicia en 1492 con la llegada de los europeos. Serán estas ciencias sociales los referentes para la creación epistémica del pensamiento humanista en América Latina. A su vez, las ciencias sociales minan la influencia del enfoque positivista que entrará en crisis a finales del siglo decimonónico, comenzando a diluirse conforme las ciencias sociales avanzaban y maduraban durante las dos primeras décadas el siglo XX10.

De esta manera, la Historia ocupa un papel clave para encontrar los hechos que demuestran la ruptura que sufre la cultura originaria con respecto a la imposición de un mundo eurocentrado. Se rescata un humanismo universal que refleje la praxis política, económica y social que provoque cambios significativos en las estructuras y superestructuras de las naciones latinoamericanas. Por ello, la presente reflexión destaca algunos de los intelectuales artífices de un pensamiento crítico-filosófico que envuelve como proyecto socio-histórico una realidad donde medie un nuevo orden social. Bajo este enfoque es oportuno recordar que

el humanismo es sensible a la diversidad histórica del ser humano, de sus culturas, de sus civilizaciones y lejos de defender una razón metódica o principalmente teórica, reivindica la centralidad de la razón práctica, de la phrónesis, que se alimenta tanto de la experiencia en el presente, como del estudio de la historia y del diálogo con los sabios de la Antigüedad. ${ }^{11}$

La categoría de humanismo evoca lecturas de carácter polisémico que puede derivar en diversas interpretaciones; genéricamente, se refiere a toda doctrina que destaque la dignidad del ser humano como tal y su carácter racional, que le da cualidades de autonomía y la capacidad de reconocerse y contribuir a cambios profundos en la sociedad. El humanismo como categoría universal refleja una narrativa sobre la esencia de la naturaleza humana, discurso que se enraíza en la Grecia antigua e impulsa un proceso de reflexión ético-filosófico sobre los principios cardinales del humanismo y sobre lo humano.

Como resultado surge el valor que tiene en la historia del pensamiento la categoría formal del humanismo, que puede ser interpretado desde diversos enfoques epistémicos como: el humanismo greco-latino, renacentista, cristiano, marxista, existencialista o de las corrientes antihumanistas surgidas en el siglo XX, representadas por los filósofos Martin Heidegger y Louis Althusser, entre

\footnotetext{
10 Guadarrama, Humanismo y autenticidad cultural..., 212. El positivismo fue asumido y cultivado en Latinoamérica de forma sui generis como una filosofía optimista llena de confianza en la humanidad, en la capacidad creativa de su pensamiento, en la cultura, la educación, la ciencia, en el progreso y el desarrollo industrial. Estaba aliada al liberalismo y a la defensa de la democracia y tales ideas resultaban muy avanzadas para los países latinoamericanos, recién entonces liberados en su mayoría del colonialismo español y enfrascados entonces en profundas luchas entre las oligarquías retrogradas y la naciente burguesía nacional.

11 Ambrosio Velasco Gómez, Humanismo (Ciudad de México: Universidad Nacional Autónoma de México, Instituto de Investigaciones Sociales, 2009), 6, acceso: 28 de noviembre de 2020, http:// conceptos.sociales.unam.mx/conceptos_final/437trabajo.pdf
} 
otros. De tal manera, que convierte al humanismo en un pensamiento históricouniversal.

El pensamiento crítico latinoamericano ha contribuido a ocupar un lugar especial en la emancipación cultural y política del ser humano, concretado parcialmente en la región latinoamericana y caribeña a lo largo de los siglos XX y XXI. Dicho pensamiento se ha enriquecido con constructos y con participación de otras ciencias sociales, tales como la historia y la arqueología, lo que ha facilitado verificar que ninguna sociedad o cultura ha estado exenta de haber girado sobre una determinada cosmogonía que constituye la naturaleza humana como tal. El análisis del humanismo latinoamericano en la segunda mitad de siglo XX, bajo la reflexión del pensamiento crítico-filosófico, exige ubicarse a finales del siglo decimonónico, para rescatar a José Martí, cuyo pensamiento, después de su deceso en 1895, se proyectará sobre el siglo XX, dado su protagonismo emancipador y profundamente humanista que se cohesiona con el pensamiento crítico-filosófico y la praxis. Este es el gran legado martiano para los pueblos latinoamericanos y caribeños.

De modo que, José Martí, con su producción literaria y sus compromisos políticos, de manera teórica y práctica, elevó a rango de principio el latinoamericanismo, al concebirlo como libertario, fundamentarlo en la recuperación del pasado y en el riguroso conocimiento de la realidad para formar gobernantes mejor preparados, que atendieran las exigencias de las sociedades y para posibilitar la independencia mental, al propugnar la unidad de los países de la región y la importancia de los avances científicos y técnicos como el mecanismo más eficaz de lucha contra las diversas manifestaciones del imperialismo, con lo que exhibe una profunda actitud humanista ${ }^{12}$.

En este sentido, el texto anterior vendrá a enriquecer el vocabulario libertador del pensamiento filosófico de Nuestra América, empezando por un rescate identitario y cultural con el uso del principio latinoamericanismo con sentido libertario. Se hace indispensable recurrir a la memoria histórica como requisito fundamental para recuperar y entender el pasado partiendo del conocimiento de la realidad, una realidad marcada por el avasallamiento y la alienación mental por la cual Martí luchó.

El término Nuestramericano ha sido utilizado principalmente por Horacio Cerutti y tiene sus fundamentos en el concepto Nuestra América, el cual, gracias a José Martí, ha tenido gran repercusión, al punto de llegarse a hablar de toda una tradición en torno de ello. Un pensar Nuestramericano tiene como hecho ineludible el hacerse cargo de la realidad en que se vive y del lugar en donde se está. En esta línea se encuentra una fuerte atención prestada -en nuestro caso filosófico-, un permanente interés por problemas de identidad cultural y nacional

12 Alberto Saladino García, «El latinoamericanismo de José Martí», Latinoamérica. Revista de estudios Latinoamericanos, n. 41 (2005): 151, acceso: 23 de noviembre de 2020, http://www.scielo.org.mx/scielo.php? script=sci_arttext\&pid=S1665-85742005000200149\&lng=es\&tlng=es 
y, por último, una tendencia hacia una lectura crítica y explicativa del desarrollo de las ideas ${ }^{13}$.

El desarrollo de estas ideas se inserta en un proyecto humanista liberador para América Latina durante el siglo XX, cuyos orígenes se remontan a la llegada de los europeos al Continente. Las riquezas naturales de este despertaron un apoderamiento desmedido, una imposición cultural y una visión eurocéntrica hacia los pueblos. De este modo, en la modernidad, la historia de América gira alrededor del dominio del viejo continente, así como del nuevo, dominado por un proceso de mestizaje que buscó la emancipación política y la construcción de una forma de pensar que reflejara la herencia ancestral, pero también una lucha contra todo lo que fuera colonialidad y enajenación.

Históricamente se plantea la necesidad de otra Latinoamérica con su propia identidad como forma de oponerse al dominador-colonizador. Darcy Ribeiro considera que

La presencia europea en nuestras latitudes trajo a su vez los avances técnicos e inventos [...] también introdujo en ellos una carga de conceptos, preconceptos e idiosincrasias referidos a sí misma y al resto del mundo, incluidos los correspondientes a los pueblos coloniales. [...] Estos, sufrieron, además, la degradación de tener que asumir como si se tratara de su propia imagen aquella que no era sino un reflejo de la visión europea del mundo, que consideraba a la gente colonizada como racialmente inferior debido a que era negra, (amer)india o mestiza. ${ }^{14}$

En este nuevo proceso civilizatorio dominante que se emplaza en Nuestra América, surgirá con el pasar del tiempo, un proceso remozado de discursos humanistas que lograrán, durante el siglo XX, constituir un pensamiento críticofilosófico. Todo esto dentro de las circunstancias históricas concretas y desde las visiones sociopolíticas y culturales-identitarias que van a servir de soporte contra la dominación colonial y neocolonial, inaugurando una nueva era emancipatoria.

Tanto durante el siglo XIX como en el XX, ha surgido un nutrido conjunto de pensamientos que deslumbran las condiciones históricamente humanas, son tendencias que defienden la identidad, la libertad y la dignidad de los pueblos Latinoamericanos y del Caribe. Además, profundiza dos elementos fundamentales en el quehacer intelectual; por un lado, queda inmerso en su análisis desde la visión de la historia de las ideas y, por otro, robustece el pensamiento crítico y filosófico de Nuestra América.

\footnotetext{
13 Aldo Ahumada Infante, «La filosofía Nuestramericana en la filosofía chilena: una mirada a la segunda mitad del siglo XX», Intus-Legere Filosofía 6, n. ${ }^{\circ}$ (2012): 50, acceso: 3 de diciembre de 2020, http:// www.academia.edu/download/36563486/DialnetLaFilosofiaNuestroamericanaEnLFilosofiaChilena4510586.pdf La filosofía latinoamericana -nuestroamericana- debe tener como condición indispensable la mirada puesta en su contexto; si dicha mirada contiene en sí una posición y función política, como la de reafirmarnos como latinoamericanos (...)

14 Darcy Ribeiro, Las Américas y la civilización. Proceso de formación y causas del desarrollo desigual de los pueblos americanos (México: Siglo XXI, 1971), 63./2430/243016300012.pdf
} 
Con el fin de cumplir las inquietudes y perspectivas sobre la existencia de un humanismo latinoamericano, se extraen fracciones del pensamiento de quienes han pretendido rescatar una cultura y una identidad netamente americanista, ya sea con el aporte de ideas o de la praxis académica o revolucionaria. En este sentido, la mirada se dirige a José Martí, José Enrique Rodó y José Carlos Mariátegui, lo que permite profundizar en el tema durante las últimas décadas del siglo XIX, hasta la muerte de Mariátegui, el 16 de abril de 1930.

Quizás el pensamiento martiano represente el mejor paradigma liberador de Nuestra América en el ocaso del siglo XIX, pero su legado se proyecta y se materializa durante el siglo XX mediante el fortalecimiento y enriquecimiento de sus ideas, en acciones y gestas liberadoras anticoloniales y antiimperialistas que se configuran en la región de América Latina y el Caribe. Fue en 1895 cuando José Martí, mediante la praxis política, logra darle continuidad a las acciones independentistas de Carlos Manuel de Céspedes que se inician con el Grito de Yara, el 10 de octubre 1868, dando libertad a sus esclavos como un gesto humanista. Esta lucha por la independencia fue cimentada por Martí con la organización y participación de los sectores populares prevaleciendo los sectores negros y mulatos y caracterizados por singularidades históricas. Se trataba de una doble lucha: una por la emancipación definitiva del imperio español y otra por oponerse al emergente e interventor imperialismo estadounidense, como quedará demostrado para 1898 con el caso cubano.

Simultáneamente, en la última década del siglo XIX, el sistema mundial entró en una dinámica marcada por la hegemonía de Estados Unidos, hecho que repercute en el surgimiento de nuevas posiciones discursivas críticas en sectores de la intelectualidad latinoamericana y caribeña, que desde sus propias visiones pretenden encauzar la construcción de un pensamiento autóctono que reivindique la propia cultura. Definitivamente la guerra de Cuba de 1898 marca un antes y un después del pensamiento crítico latinoamericano, al evidenciar una nueva realidad; parafraseando a Beorlegui, el cambio de sensibilidad se dirige a un rechazo de la cultura española, a la que se le achaca el retraso americano, y una admiración hacia los Estados Unidos como un modelo de progreso, pero que a su vez es el producto de una desconfianza por la expansión imperialista estadounidense, como ya se venía dando desde mediados del siglo XIX, con la expropiación de grandes extensiones de su territorio a México y la aplicación de doctrinas políticas interventoras (Doctrina Monroe) que pretendían someter y dominar las nuevas Repúblicas y territorios al sur del río Grande ${ }^{15}$.

En este contexto histórico surgen intelectuales como José Martí y José Enrique Rodó (1871-1917). Interesa, en este trabajo, mencionar las enseñanzas de Rodó, para señalar su aporte e interpretar el pensamiento humanista y liberador que se perfila en el continente americano. Dentro de esta coyuntura histórica se definirán, de alguna manera, los posicionamientos en el pensar eurocéntrico y 
estadounidense. José Enrique Rodó será parte de esa generación que incita al debate en el ámbito de la nueva «historia de las ideas».

La historia de las ideas, referida en particular a la filosofía, tuvo sus comienzos en las polémicas del siglo XIX, [...] Las polémicas a las que nos referimos, pusieron énfasis en la función social de la idea, respecto de nuestra realidad americana. [...] Entre fines del siglo XIX y comienzos del XX, la historiografía de las ideas y dentro de ellas, en particular, de las filosóficas, se generalizó en los principales centros culturales del Continente. ${ }^{16}$

La guerra de Cuba, en 1898, no solo será el acontecimiento que tuvo gran influencia en deliberar y enfocar la situación y la identidad en América, sino que provoca la aparición de Ariel. Durante la última década del siglo XIX aparecen dos obras importantes: la publicación del ensayo de José Martí Nuestra América, en 1891, y de José Enrique Rodó con el Ariel en 1900. Jenkins considera que «Ambos escritos transmiten la auténtica preocupación por el bienestar de América Latina que sus autores sinceramente sentían a lo largo de sus carreras literarias» ${ }^{17}$. Para Jenkins ${ }^{18}$

el Ariel [...] significaba un producto del «criollo exótico» y que contrasta mucho con la visión revolucionaria de Nuestra América, [...] Nuestra América, es en verdad, radical, sobre todo para su época, de modo que realmente se le puede calificar a Martí de precursor del pensamiento moderno de América Latina.

En los inicios del siglo XX se nota un salto cualitativo en la maduración del movimiento intelectual latinoamericano, al surgir posiciones que superan las ideas positivistas heredadas del siglo pasado. «Esta generación de entre siglos se irá desmarcando de lo anglosajón para volver la vista a los valores de la cultura hispana, con el predominio del humanismo, la creatividad artística y la solidaridad» 19 .

Entre estas corrientes se destaca el caso de José Carlos Mariátegui y de otros teóricos que buscan lograr una cierta identidad e intensidad de reflexión y de profundidad de la cultura latinoamericana, sin darles mayor importancia a la europea y la norteamericana, tratando de rescatar la presencia del elemento indígena. A Mariátegui le corresponde vivir un contexto en el cual se producen acontecimientos de enorme importancia en los procesos de construcción de una teoría auténticamente americanista. Mariátegui nace en 1894 y muere en 1930, periodo marcado por la Revolución mexicana y por la presencia de dos de los más connotados luchadores en favor de las masas campesinas sin tierra, como lo fueron Emiliano Zapata y José Doroteo Arango Arámbula, conocido como Francisco Pancho Villa. Otro de los acontecimientos históricos que marcaron a

16 Arturo Andrés Roig, La Historia de las ideas, teoría del discurso y pensamiento latinoamericano (Bogotá: Universidad Santo Tomás, 1993), 14, acceso: 30 de noviembre de 2020, https:// unamiradafilosofica.files.wordpress.com/2013/07/roig-1993.pdf

17 Ryan Jenkins, «Ariel y Calibán, Rodó y Martí», Gaceta Hispánica de Madrid (2006): 1, acceso: 25 de noviembre de 2020, http://www.gacetahispanica.com

18 Jenkins, Ariel y Calibán..., 1.

19 Beorlegui, Historia del pensamiento..., 360. 
algunos pensadores de Nuestra América fue la Revolución bolchevique de 1917, que venía a implantar un nuevo orden sociopolítico dentro del mundo capitalista que estaría orientado por las tesis del marxismo-leninismo.

La escuela de Mariátegui se basa en cinco pilares que gozan de actualidad: el problema del indio; el socialismo creativo, especialmente la confluencia del socialismo y el indigenismo; el movimiento vanguardista expresado en la política, la cultura y el arte; la preocupación por la escena contemporánea, sobre todo la relación de lo nacional con lo internacional; y, por último, el americanismo como proceso identitario. Durante este periodo de finales del siglo XIX y primeras décadas del siglo XX, aparecen otros intelectuales cuyos aportes no puede dejar de señalarse.

El mexicano José María Vasconcelos Calderón (1882-1959), bajo la concepción de la esencia del ser humano, busca la conformación de un hombre nuevo: el hombre lberoamericano y la necesidad de promover una cultura nacional y popular inclusiva a todos los mexicanos. Vasconcelos se planteaba un nuevo humanismo para América Latina. Hablaba de una «cultura cósmica, ya que la raza cósmica representa la identidad de los pueblos iberoamericanos forjadores de una nueva raza, gestora del hombre nuevo y prototipo de los anhelos del género humano» ${ }^{20}$. En su obra filosófica humanista existe un mundo en relación con la humanidad, estético culturalmente hablando, que contribuyó enormemente en la formación humana.

Había llegado un momento histórico que facilitaba las circunstancias del desarrollo de un pensamiento arraigado en lo latinoamericano: los acontecimientos revolucionarios que surgen en México en 1910 orientan e intentan encontrar expresiones culturales nacionalistas y autóctonas que serán expresadas en las obras pictóricas del muralista Diego Rivera (1886-1957), considerado el portavoz de los oprimidos y de los indígenas, por ello se le considera el pintor de la identidad mexicana; José Clemente Ángel Orozco Flores (1883-1949), muralista, comprometido con las causas sociales, algunas de sus obras reflejan su filosofía humanista; David Alfaro Siqueiros (1896-1974), su obra estuvo influenciada por el marxismo lo que evidencia su carácter ideológico y político. El trabajo artístico y las obras de Rivera, Orozco y Siqueiros, trascienden en el reconocimiento internacional en un evidente interés por el diálogo filosófico del momento.

Era un momento para no mirar más allá de las fronteras latinoamericanas, se trataba de pensar cómo crear una filosofía y una cultura con características latinoamericanas, donde no existieran espacios de dominación económica,

20 Beorlegui, Historia del pensamiento..., 421. Vasconcelos consideraba que América era el continente capaz de realizar esa síntesis, de lograr la «raza cósmica», basada en una igualdad esencial de todos los seres humanos, pero sin implicar tal igualdad la uniformidad que superara las diferencias, puesto que proponía conjugar la unidad mestiza con la diversidad de razas, nacionalidades, colores, culturas, etc. 
política y menos cultural de los Estados Unidos, sobre todo después del Calibán ${ }^{21}$ surgido con los acontecimientos imperialistas de 1898 en la guerra contra el decadente imperio español. El pensamiento crítico latinoamericano, como instrumento identitario y liberador del pueblo americano, estará presente en la filosofía, la literatura y la pintura.

En este contexto se recuerda Nuestra América de Martí el cual plantea sus ideas y argumentos relevantes para la América Latina por tener plena vigencia en el presente. A Nuestra América se le puede considerar como la precursora del pensamiento moderno en América Latina por su visión revolucionaria y radical sobre temas como cultura, raza e identidad. Nuestra América satisface la crisis de identificación que por tanto tiempo ha preocupado a los intelectuales de América Latina al exigir el ser americano. José Martí concreta un mensaje profundamente humanista: «patria es humanidad», «Con los pobres de la tierra/ quiero yo mi suerte echar»22.

Los acontecimientos que se desarrollan en Europa en la década de los treinta, y concretamente en España como producto de la guerra civil (1936-1939), obliga a un nutrido y excelente grupo de intelectuales a emigrar a América Latina, entre ellos venía José María Gaos (1900-1969) que residirá a partir de 1938 en México desde donde dará una enorme contribución filosófica a la deliberación humanista. Su mayor aporte fue forjar la escuela hispanoamericana de filosofía al promover y propugnar entre sus discípulos tanto tópicos de historia de las ideas como de reflexión filosófica original en varias disciplinas y corrientes. En el decir de Leopoldo Zea: Gaos quería que sus discípulos aprendiesen a filosofar, a aportar solo si hacían algo más que difundir, repetir los temas de moda23. Gaos no solo alcanzó los méritos de lograr compenetrar en la historia de México bajo su condición de exiliado, dando pie a una historia de la filosofía, sino que además ayudó a reconocer y promover la existencia misma del quehacer filosófico hispanoamericano llamar la atención de la importancia del pensamiento de Nuestra América.

\footnotetext{
21 Fernández Retamar, Pensamiento de nuestra... Ante el cuestionamiento de la existencia de una cultura latinoamericana, realizó un desmontaje de las lecturas de Calibán que parten del discurso europeo para situarlo -frente a la afirmación arielista de Rodó- como nuestro paradigma de resistencia, «conceptometáfora» de un sujeto poscolonial que se revela desde el lenguaje y desde la cultura: «Nuestro símbolo no es pues Ariel, como pensó Rodó, sino Calibán. Esto es algo que vemos con particular nitidez los mestizos que habitamos estas mismas islas donde vivió Calibán: Próspero invadió las islas, mató a nuestros ancestros, esclavizó a Calibán y le enseñó su idioma para entenderse con él: ¿Qué otra cosa puede hacer Calibán sino utilizar ese mismo idioma para maldecir, para desear que caiga sobre él la «roja plaga»? No conozco otra metáfora más acertada de nuestra situación cultural, de nuestra realidad (...), ¿qué es nuestra historia, que es nuestra cultura, sino la historia, sino la cultura de Calibán?» Ver: Colaboradores de EcuRed, Calibán personaje, acceso: 14 de marzo de 2021,

https://www.ecured.cu/index.php?title=Calib\%C3\%A1n_(personaje)\&oldid=3797408

22 Extracto de Versos Sencillos (iii) del poeta cubano José Martí. Ver: José Martí. Selección y notas de Alfonso Chase y Dennis Mesén; pról. de Roberto Fernández Retamar. San José: Ministerio de Cultura, Juventud y Deportes, Departamento de Publicaciones, 1976: 554.

23 Saladino, El latinoamericanismo..., párrafo 6.
} 


\section{El humanismo latinoamericano y caribeño de la segunda mitad del siglo XX}

El pensamiento crítico se proyecta como el núcleo fundamental de una serie de movimientos de reflexión donde prima la preocupación por la realidad latinoamericana, lo que llevó a impulsar una plataforma de ideas para darle respuestas a los graves problemas de desarrollo y de pensamiento identitario a partir del momento en que el continente americano fue colonizado por el europeo. El carácter de esta reflexión se ha direccionado hacia la necesidad de rescatar la construcción de una auténtica historia latinoamericana y caribeña, olvidada o manipulada por los bloques de poder internos y externos. Se pretende reafirmar la identidad y soberanía al desarrollar procesos emancipatorios o libertarios que permitan a los pueblos latinoamericanos un camino diferente, con miras a una nueva realidad socio-política y económica alejada de las opresiones y desigualdades, donde prevalezca el bien común y la plena vigencia de los derechos humanos.

Diversos movimientos y organizaciones sociales, políticas y culturales a lo largo de Nuestra América o Abya Yala, muestran que la lucha liberadora de los pueblos no se detuvo. La Historia de las Ideas, la Teoría de la dependencia, el socialismo latinoamericano, el indianismo o las filosofías y teologías de la liberación son algunos ejemplos relevantes de ello. El deseo de lo posible, nunca alcanzado plenamente, pero indispensable para potenciar la emancipación, ha producido una reflexión en la cual se articulan y disputan diversos cruces epistémicos, entre ellos la ideología, la filosofía y las ciencias sociales ${ }^{24}$.

En general, estas tendencias defienden la libertad, la autenticidad y la dignidad de los individuos como único motor para el desarrollo de un humanismo más integral, que contemple una nueva escala de valores. El humanismo latinoamericano y caribeño, en su esfuerzo, recoge lo mejor de ese pensamiento transformador de las realidades sociales y del ser humano. «En este sentido, es el punto de vista de la humanización de las relaciones humanas mismas y de la relación con la naturaleza entera. Emancipación es humanización, y humanización desemboca en emancipación» 25 .

De tal forma que, al irrumpir la segunda mitad del siglo XX, los pueblos latinoamericanos se vieron comprometidos a (re)pensar e impulsar un pensamiento liberador apegado a las realidades concretas sociales, políticas y culturales con las que se enfrentaban bajo la égida de la colonialidad. Quijano, en su obra Colonialidad del poder y clasificación social, enfatiza que la

\footnotetext{
24 Horacio Cerutti Guldberg et al., «Filosofar desde sujetos y procesos liberadores de Nuestra América», en: Estudios latinoamericanos: diálogos interdisciplinarios sobre sociedad, historia, cultura, Frontera y territorio de María Laura Gili y Graciana Pérez Zavala, $1^{a}$ ed. (Buenos Aires: Aspha, 2015), 107, acceso: 28 de noviembre de 2020, https://www.academia.edu/37170559/Cap_Sujetos

25 Franz Hinkelammert, Pensamiento crítico y crítica de la razón mítica (San José: CLACSO, 2007), 43, acceso: 21 de noviembre de 2020, http://bibliotecavirtual.clacso.org.ar/Costa_Rica/dei/20120706111924/ pensamiento.pdf
} 
Colonialidad es un concepto diferente, aunque vinculado con el concepto de colonialismo. Este último se refiere estrictamente a una estructura de dominación y explotación, donde el control de la autoridad política, de los recursos de producción y del trabajo de una población lo detenta otra de diferente identidad, y cuyas sedes centrales están, además, en otra jurisdicción territorial. Pero no siempre, ni necesariamente, implica relaciones racistas de poder. El colonialismo es, obviamente, más antiguo, en tanto que la colonialidad ha probado ser, en los últimos quinientos años, más profunda y duradera que el colonialismo. ${ }^{26}$

El siglo XX se configuraba como el siglo de las imposiciones mediatizadoras, colonizadoras y de intentos descolonizadores que configuraron visiones de un nuevo pensamiento crítico latinoamericano. En esta orientación se ubican los proyectos des-colonial del peruano Aníbal Quijano (1928-2018) y de Walter Mignolo (1941-). Quijano, mediante su pensamiento, contribuye a rupturas epistemológicas con la introducción del concepto de la colonialidad del poder, formulada a principios de los años noventa y ampliada por la red de intelectuales activistas del Proyecto Modernidad / Colonialidad / Descolonialidad, como una de las propuestas epistémicas más debatidas en el escenario intelectual contemporáneo en América Latina. Entre algunas de sus obras se citan: Colonialidad del poder y subjetividad en America Latina; Colonialidad del poder y clasificación social. En esta última, Quijano parte de que

la colonialidad es uno de los elementos constitutivos específicos del patrón mundial de poder capitalista [...] con América (Latina) el capitalismo se hace mundial, eurocentrado y la colonialidad y la modernidad se instalan, hasta hoy, como los ejes constitutivos de este específico patrón de poder. Se funda en la imposición de una clasificación racial / étnica de la población del mundo como piedra angular de dicho patrón de poder, y opera en cada uno de los planos, ámbitos y dimensiones, materiales y subjetivas, de la existencia cotidiana y a escala cotidiana y a escala societal. ${ }^{27}$

La categoría de colonialidad de Quijano es hija del capitalismo como «un sistema social histórico», tal y como lo llamó Wallerstein ${ }^{28}$, puesto que sus raíces se encuentran con la conquista europea a partir de 1492 y que motivó una de la acciones más antihumanistas con la inauguración de la modernidad: contribuyó a la reestructuración de las sociedades naturales encontradas en América, creando un patrón dominante sobre el concepto de raza como una clasificación de dominio social en el ámbito de la especie humana. Este dominio del poder contemplaba la definición de nuevas identidades frente a las originales que modificaron los imaginarios y las cosmovisiones en general. Desde estas imposiciones nace la colonialidad del poder como imposición deshumanizante.

Quijano, en su obra Colonialidad del poder, eurocentrismo y América Latina, conduce a la vertiente poscolonial que denomina colonialidad del poder, el cual

\footnotetext{
26 Aníbal Quijano Obregón, Colonialidad del poder y clasificación social (San José: CLACSO, 2014), 285, acceso: 1 de diciembre de 2020, http://biblioteca.clacso.edu.ar/clacso/se/20140506032333/eje1-7.pdf 27 Quijano, Colonialidad del poder..., 285.

28 Immanuel Wallerstein, El capitalismo histórico (Madrid, Siglo XXI de España editores, 1988), 1.
} 
es el producto de una serie de elementos identificados con el inicio del periodo colonial, donde América consolidó la internacionalización o globalización en el marco del capitalismo colonial-moderno y eurocentrado. Se podría decir que la convergencia modernidad y colonialidad del poder conforman un proceso histórico o sistema-mundo, que estructura el sistema capitalista actual. De tal manera, ese patrón de poder es la clasificación social sobre la idea de raza, como forma de organización social del poder hegemónico que se concretará en el Estado-nación una vez llegado el ciclo de independencia en las colonias americanas y donde prevalecerá la visión del eurocentrismo.

Partiendo de los aportes de Quijano, Walter Mignolo profundiza sobre el tema de la colonialidad desde tres nociones: ser, saber y poder. Estas tres nociones permiten comprender cómo se construyó y se consolidó un pensamiento hegemónico concretado durante la modernidad, con una lectura donde se colonizan los imaginarios, el pensamiento por medio de la lengua, la legitimación de identidades por medio de instituciones y leyes que legalizan la gobernabilidad de los territorios arrebatados por la enajenación de los ciudadanos.

La colonialidad del ser se refiere, entonces, a la experiencia vivida en la colonización y su impacto en el lenguaje. En otras palabras, la colonialidad del ser pasa por los imaginarios del cómo entender el sujeto, el tiempo y el espacio en concordancia con la idea de la modernidad europea y cuándo el pensamiento se ha colonizado por medio de la lengua. Para América Latina representó la creación de mecanismos de control que legalizaron identidades por medio de instituciones, discursos y legislaciones que facilitarán las gobernanzas tanto de territorios como de los pobladores. Maldonado-Torres, citando a Mignolo sobre el tema de la colonialidad del ser, aclara:

los lenguajes no son solo fenómenos culturales en los que la gente encuentra su identidad; estos son también el lugar donde el conocimiento está inscrito. Y si los lenguajes no son cosas que los seres humanos tienen, sino algo que estos son, la colonialidad del poder y del saber engendra, pues, la colonialidad del ser. ${ }^{29}$

En resumen, para los estudios en este campo del saber sobre lo decolonial, no hay modernidad sin colonialidad ni tampoco hay colonialidad sin modernidad. Es decir, que como hecho histórico son conceptos analíticos entrecruzados. En este sentido, la colonialidad del ser y del saber debe observarse como proceso que conformó un modelo de pensamiento hegemónico que se extendió en las sociedades coloniales. Está ligado con los diversos ámbitos de la vida, por lo que se habla de la colonialidad del ser o de los modos de subjetividad, colonialidad

\footnotetext{
29 Nelson Maldonado Torres, La colonialidad del ser: contribuciones al desarrollo de un concepto, en Santiago Castro-Gómez y Ramón Grosfoguel, El giro decolonial. Reflexiones para una diversidad epistémica más allá del capitalismo global (Bogotá: Universidad Javeriana-Instituto Pensar, Universidad Central IESCO, Siglo del Hombre, 2007), 130, acceso: 25 de noviembre de 2020, http://www.unsa.edu.ar/histocat/hamoderna/ grosfoguelcastrogomez.pdf
} 
del saber o de los modos de conocimiento y colonialidad del poder o de los modos de organización. De ahí que surgen propuestas de transformación para la descolonización del ser, del saber y del poder que la mentalidad europea buscó imponerse por sobre las mentalidades de los territorios conquistados en América. Esta situación llevó a la marginalización y subalternización de los modos de creer, pensar, hablar, de los pueblos originarios. Se implantó en el Continente un sistema de colonialismo de poder.

En esta mirada retrospectiva de la historia del pensamiento latinoamericano humanista, se hace referencia, principalmente, a dos figuras cimeras que crearon un gran debate del pensamiento filosófico, que para efectos de este estudio, se ubican en la década de los cincuenta del siglo XX. Se trata del mexicano Leopoldo Zea Aguilar (1912-2004) y del peruano Augusto Salazar Bondy (1925-1974). Ambos creen en la necesidad de hacer una filosofía auténtica, original. Salazar Bondy aborda el problema del pensamiento filosófico hispanoamericano en su obra: ¿Existe una filosofía de Nuestra América? y considera que este pensamiento se inicia con la introducción de las corrientes predominantes en la España de la época de la Conquista, enmarcado en un sistema político y eclesiástico oficial de educación con la finalidad de imponer las ideas y los valores permitidos por el Estado y la Iglesia a los pobladores de América. Así, los hispanoamericanos aprenden como primera filosofía un sistema de ideas que obedecen a los europeos de España.

Zea plantea la necesidad de un reencuentro con el pasado histórico, recogiendo lo más destacado de este. Salazar Bondy toma una posición más radical, entiende que hay que romper con el pasado, pero no es necesario, puesto que en ningún momento del pasado se filosofó como para lograr hacer filosofía auténticamente americana, la que considera solo se podrá producir cuando se disponga de condiciones auténticas de liberación.

Salazar Bondy abre el debate cuando lanza la pregunta ¿Existe una filosofía de Nuestra América?, a la que Leopoldo Zea le responde con La filosofía sin más, de tal manera que las posiciones que se derivan de la polémica serán los antecedentes de lo filosófico latinoamericano dando pie a la filosofía de la liberación. Zea demuestra que los filósofos que pensaron en América Latina eran filósofos auténticos y originales, pero lo hacían con cierto estilo colonial puesto que partían de las ideas de los filósofos europeos o norteamericanos. Por su lado, Salazar Bondy se ubica en un contexto sociopolítico y económico de la cultura latinoamericana, en la medida de la existencia de lo colonial o dependencia que influyó a la vez en lo epistemológico y esta razón no permitía pensar auténticamente. A ambos pensadores se les considera precursores de la llamada Filosofía de la Liberación.

La figura intelectual de Leopoldo Zea es una de las de más peso dentro de la historia del pensamiento filosófico hispanoamericano. Ubicado dentro de la línea 
denominada afirmativa30; Zea, como lo señala Carlos Beorlegui, al referirse a Francisco Miró Quesada, piensa que ha llegado el momento de filosofar auténticamente y que la forma de hacerlo es tomando conciencia de la historia del pensamiento de épocas anteriores. La realidad humana está constituida por la historia, por lo que resulta imprescindible conocer la historia de las ideas. Y al examinar esa historia se manifiesta la existencia de un legado filosófico.

En sus reflexiones llegó a descubrir la filosofía de la historia como aquella búsqueda de la esencia ontológica del ser latinoamericano y el conocimiento de la auténtica expresión de sus pueblos. Zea defendió la idea del Encuentro de Culturas, pues la identidad de Nuestra América se halla tanto en lo indígena y en lo europeo, como en todos los pueblos y culturas que han llegado a estas tierras, convertidas en síntesis de la cultura universal. Ante los defensores de la idea del descubrimiento de América, Zea señaló que no hubo descubrimiento, sino encubrimiento de América, pues ocurrió la acción de Europa conquistadora y dominante que ocultó el desarrollo y los adelantos de las culturas aborígenes, entre ellas los aztecas, los mayas, los incas y los chibchas.

Avanzado el siglo XX el pensamiento latinoamericano toma diversos perfiles que se plasman en contextos desiguales donde cada representante aporta a la validación de una identidad propia. Como ya se mencionó en los antecedentes, será Rodó y su arielismo, una posición de reivindicación culturalista que busca lo propio, facilitando un periodo nacionalista convergente. Hechos como la crisis económica mundial de 1929 se centran en la defensa de las economías nacionales en busca de nuevas formas de identitarismo y culturalismo, matizándose con lo social.

En las décadas de los cuarenta y cincuenta, bajo la acción del Consejo Económico para América Latina (CEPAL), se profundiza un proyecto de industrialización encabezado por Raúl Prebisch y pensadores sociales, con una nueva interpretación novedosa de la economía. Esta corriente, sin embargo, se debilita como tendencia identitaria. La Revolución cubana, aparejada a las ciencias sociales, recurre al concepto de dependencia, de la cual Fernando $\mathrm{H}$. Cardoso fue uno de sus principales representantes; pero, a la vez, toma impulso la educación del oprimido, la educación liberadora de Freire, la teología de la liberación con Gustavo Gutiérrez y la filosofía de la liberación con Zea. A partir de mediados de la década de 1970, se impone la propuesta neoliberal que se materializará en los ochenta como proyecto modernizador.

Ante estos bosquejos históricos se implanta la realidad por donde transitan los pueblos latinoamericanos, la reflexión se apoya en las ideas creadoras y liberadoras que han penetrado en contextos concretos para crear fuerzas de autonomía y de verdadera independencia de los pueblos latinoamericanos y

30 Beorlegui Rodríguez, Historia del pensamiento..., 558-559. Frente a la postura asuntiva, que centra sus esfuerzos en asimilar la filosofía europea y norteamericana y se demora en su empeño por crear una filosofía original y autóctona, la línea afirmativa, partiendo de la inevitable condición de perspectivística y circunstanciada de la filosofía, centra todos sus esfuerzos en filosofar desde la problemática latinoamericana. 
caribeños. Es por ello que se encuentra en los discursos de los pensadores analizados, en categorías como dependencia y liberación. Es el replantearse una América libre con su propia identidad, es buscar un nuevo humanismo integral, pensando que existen muchos humanismos y pensadores que lo visualizan según el contexto socio histórico y así lo analizan. Pero sí queda claro que el humanismo, en general, consiste en una afirmación de la dignidad del ser humano.

En los escritos de Salazar Bondy y en sus personajes (Bartolomé y Hatuey) ${ }^{31}$ se introduce la práctica de la dependencia, alienación y dominación para reflejar que el alienado pierde la conciencia de sí, del sentido de sus actos. Son escenarios históricos creados por los mismos seres humanos, el mundo se vuelve extraño y ellos están fuera de sí. El estado de alienación implica que las decisiones acerca de la vida de un sujeto dependen de otro o su voluntad está dominada por la voluntad de otro. Augusto Salazar Bondy, en su pensamiento humanista, lo construye teóricamente sobre el eje de la historicidad de todo lo humano32.

La presencia de la llegada del europeo y su cultura se convierte en el sustento crítico de la mayoría de pensadores humanistas del continente latinoamericano y del Caribe, siendo esta una posición básica para entender el antes y el posterior desarrollo histórico de sus naciones y de sus identidades. Y no podía ser de otra manera, porque la imposición se dio, desde cualquier punto que se mire y basta un solo ejemplo semántico: América, fue impuesto desde Europa.

Arturo Andrés Roig señala que

la recurrencia casi obsesiva del problema del sujeto en el pensamiento latinoamericano tiene relación con la violencia, el despojo y la objetivación total de la humanidad americana que representó la conquista de América; como consecuencia de ello, los americanos, en tanto pueblos sometidos y negados en su subjetividad, experimentarían en adelante la necesidad de preguntar por su identidad. Se trata de una necesidad de expresarse, de saberse, de reconocerse en su universal condición humana y en su especifica determinación social, cultural, espiritual; necesidad experimentada por diferentes grupos humanos

\footnotetext{
31 Eugenio María de Hostos y Augusto Salazar Bondy», Revista Ágora 10, n. 19-20 (2009): 25, acceso: 2 de marzo de 2021, http://www.agoraphilosophica.com/Agora19-20/agora19-20-arpini.pdf. Los personajes que intervienen son: Bartolomé, alude a Bartolomé de Las Casas: es el personaje a través del cual el autor conduce la argumentación y expresa preferentemente sus propias opiniones. Don Diego, Gobernador y Repartidor Real de los indios: representa la voz del conquistador español. Hatuey, cacique de Guahabá, que cuando acepte ser bautizado llevará el nombre de Ernesto, nombre que significa «combatiente decidido», en alusión a Ernesto Che Guevara. Micaela, mujer de la aldea Guahabá. Ginés, alude a Ginés de Sepúlveda, es la figura del intelectual que enfrenta, apoyándose en «los mejores autores», los argumentos de Bartolomé y de Hatuey. También se opone a Frans. Frans, caracterizado como «hombre de África y América», es una referencia directa al autor de Los condenados de la Tierra, Frans Fannon. Adriana Arpini, «Utopía y humanismo en el pensamiento latino americano»: Eugenio María de Hostos y Augusto Salazar Bondy», Revista Ágora, n. ${ }^{\circ}$ 19-20, Vol. X (2009): 25, acceso: 2 de marzo de 2021, http://www.agoraphilosophica.com/ Agora19-20/agora19-20-arpini.pdf

32 Augusto Salazar Bondy, «Bartolomé o de la Dominación», en: Dominación y liberación. Escritos 1966-1974.

Edición de Helen Orvig y David Sobrevilla (Lima: Fondo Editorial de la Facultad de Letras y Ciencias Humanas, Universidad Nacional Mayor de San Marcos, 1995).
} 
insertos en lo que José Martí llamó «Nuestra América», del pasado y del presente, que, por su condición subalterna, luchan por romper con el estado de cosas instituido, desde el descubrimiento hasta la actualidad. ${ }^{33}$

Este proceso de subjetividad es descrito duramente por Roig como posterior a la aparición del europeo, la población nativa tiene que iniciar un resurgimiento del sujeto americano. La historia de este re-surgir es la historia del continente. Roig recuerda al padre Bartolomé de las Casas que considera que el hombre nativo no puede alzar su voz para defenderse. Roig entendió la historia americana en ese largo recorrido de dominación y de reclamo por una segunda independencia propuesta de sujetos y de movimientos que plasman ese humanismo que pasa por toda la historia latinoamericana. Roig, con sus grandes cualidades intelectuales, profundizó en muchos aspectos de su fructífero trabajo y logró rescatar un pensamiento de ideas humanistas ${ }^{34}$.

Arturo Roig, en Bases metodológicas para el tratamiento de las ideologías, dice que

todo oprimido se siente en cuanto tal, por naturaleza, fuera del sistema (... por ello) las ideologías de los oprimidos y las filosofías de la liberación (en plural por primera vez) se ocupan por eso mismo del futuro, entienden la historia como un proceso permanente de irrupción de lo nuevo. ${ }^{35}$

A partir de esta perspectiva la filosofía de la liberación debe plantearse como la liberación del hombre que en su conjunto se interpreta como la liberación de los pueblos, del hombre «universal sin más». Como lo rescataban Salazar Bondy, Dussel y Fanon, que hablan de la humanidad nueva y de la nueva filosofía de esa humanidad, la filosofía ha sido una filosofía de la liberación, como lo planteaba Zea en 1974. Testimoniado en la obra de F. Fanon, Los condenados de la Tierra, con el famoso prólogo de Jean-Paul Sartre, quien expone una posición firme y clara: después de la colonización implantada con violencia, viene la cultural.

Se le otorga a un determinado grupo indígena el privilegio de pertenecer e incluso se lo forma en los valores de occidente. De tal manera que deseche sus propios principios y adopte ese humanismo eurocéntrico que en realidad se le impone y lo utilice a su vez, como base para reclamarle al conquistador por su falta de humanismo. Ante este antihumanismo, Fanon alzó la voz cuando

\footnotetext{
33 Estela Fernández Nadal, «El humanismo latinoamericanista de Arturo Andrés Roig», Utopía y Praxis Latinoamericana 17, n. 59 (2012): 13, acceso: 17 de noviembre de 2020, https://www.redalyc.org/ articulo.oa? $\mathrm{id}=27925537008$

34 Fernández Nadal, El humanismo latinoamericanista..., 17. En definitiva, la nueva comprensión de las «ideas» historiadas, que impulsó Roig a partir de los setenta, permitió incorporar una serie de herramientas aptas para descubrir la presencia del contexto social en los textos e incluso para leer, en la superficie de los textos políticos, sociales o filosóficos latinoamericanos, las voces «otras» (de los «otros» silenciados o eludidos en cualquier discurso), los debates y disputas entre proyectos sociales o políticos diversos (no siempre explícitos en los textos), los diferentes sujetos sociales que pugnan por imponer sus proyectos en determinado momento y lugar, etcétera.

35 Enrique Dussel, Eduardo Mendieta y Carmen Bohórquez, Editores, El pensamiento filosófico latinoamericano, del Caribe y «latino» (1300-2000): historia, corrientes, temas y filósofos (Ciudad de México, Siglo XXI Editores, 2009).
} 
recuerda que Europa habla de humanidad pero es una humanidad que se asesina al mismo tiempo, reflejando el gran cinismo del europeo. Por esto, como lo señala Katherine Walsh, «Para Fanon, la humanización es el eje central del proceso de descolonización, de descolonizarse y, por ende, de liberación» 36 .

La creación de un pensamiento liberador desde la visión de un humanismo integral pasa necesariamente por Latinoamérica en el rescate mismo de su historia cultural que se remonta no a la llegada de los españoles, sino al rescate de todo el pensamiento y enseñanzas aportadas por los pueblos ancestrales. Este será el dilema de la construcción de una verdadera cultura y pensamiento latinoamericano y caribeño que deberá materializarse en una segunda emancipación. Y tal como lo plantea la Filosofía de la Liberación dicha emancipación ya tiene sus soportes, desde los cuales se pueden impulsar y profundizar nuevos cambios que son las revoluciones contemporáneas, a saber: La cubana (1959), la revolución democrática socialista de Allende (1970), la revolución sandinista (1979), la zapatista (1994), la bolivariana (1999), la boliviana (2006), las acciones armadas revolucionarias del movimiento Farabundo Martí para la Liberación Nacional de El Salvador (1980-1992) y muchos otros movimientos liberadores que a mediano y largo plazo crearán nuevas reflexiones.

Esta mirada de la concreción de un humanismo latinoamericano, visto desde la óptica de posiciones liberadoras en lo cultural y socioeconómico, ha sido debatida después de inicios de la quinta década del siglo XX por sociólogos, economistas y filósofos fundamentados en obras aportadas por Orlando Fals Borda en Sociología de la Liberación o en fuentes sociológicas aportadas por Camilo Torres, así como el caso de Freire con su Pedagogía del oprimido, entre muchos otros. El concepto de liberación se le achaca a Marcuse, que vino a trascender los espacios filosóficos y políticos, puesto que muchos movimientos revolucionarios y liberadores latinoamericanos y caribeños lo adoptarán para sus movimientos de liberación nacional, al igual como ocurrió en Asia, África y América Latina y el Caribe.

El concepto de liberación cultural, como se aprecia, posee un carácter universal por plantearse luchas emancipadoras contra las imposiciones colonialistas desde las metrópolis. De ahí la importancia del papel teórico de Enrique Dussel en la reinterpretación de la historia mundial vista desde lo no eurocéntrico. En su obra Hipótesis para el estudio de Latinoamérica en la historia universal, Dussel plantea que

la proto-historia (que es la Europa occidental en último término, y en especial España) viene aquí a conjugarse en formas culturales mestizas (de la cual el «mestizaje» racial es solo un símbolo), haciendo de la historia latinoamericana algo absolutamente único [...] porque nadie podrá explicarnos sino los que

\footnotetext{
36 Katherine Walsh, Lo pedagógico y lo decolonial. Entretejiendo caminos, en: Pedagogías decoloniales: Prácticas insurgentes de resistir, (re)existir y (re)vivir. Tomo I. 1ª Ed. (Quito, Ediciones Abya-Yala, 2013): 42, acceso: 2 de diciembre de 2020, http://agoradeeducacion.com/doc/wp-content/uploads/2017/09/Walsh-2013Pedagog\%C3\%ADas-Decoloniales.-Pr\%C3\%A1cticas.pdf
} 
vivimos ese drama singular. Al nivel de la civilización -tal como la hemos definido-, vemos el derrumbe de las insuficientes civilizaciones amerindianas, para renacer a modo de injerto, una nueva civilización que no es ya ni el puro mundo hispánico ni europeo [...] América Latina no se desarrolló [...] porque su nacimiento coincide con el nacimiento del colonialismo. Es más, es el primer gran ejemplo del colonialismo europeo. De este colonialismo [...] somos las víctimas. ${ }^{37}$

La posición de Dussel no es de extrañar, el pensamiento latinoamericano debe contar con un constante enriquecimiento desde las posturas epistemológicas que marquen las pautas de ese encuentro con la búsqueda de su modernización y el reforzamiento, no solo como pensamiento debidamente estructurado, sino en la búsqueda de lo nuestro como un componente de la universalidad de los seres humanos. Este forcejeo del humanismo dentro de la historicidad latinoamericana tiene como pretensión lograr el objetivo de identificación con la convivencia humana de manera integral. En su libro, Diez ensayos críticos, Baraona Cockerell interpreta que:

Necesitamos un humanismo que integre a los individuos y todos sus derechos, que garantice el derecho a la alimentación, al trabajo, a la vivienda, a la salud y a la educación, pero como derechos gratuitos y universales [...] Que integre otra vez al ser humano a la gran red a la cual pertenece de manera indisoluble: la naturaleza. [...] Que ponga al ser humano y a sus grandes necesidades objetivas y subjetivas en el centro de la economía, la sociedad, la política y la cultura, y que integre [de manera] mancomunada [...] a la diversidad de naciones, pueblos, religiones, culturas y etnias que forman parte del enorme mosaico de la humanidad. ${ }^{38}$

Esta breve travesía por el pensamiento humanista latinoamericano y caribeño refleja como enseñanza la necesidad imperiosa de que la sociedad americana sea capaz de la construcción de un movimiento humanista apegado a su realidad social concreta, un humanismo integral y crítico que prepare la emancipación de sus pueblos con proyección hacia sociedades con justicia social. Se busca un humanismo que proponga la construcción individual y colectiva, que guie la praxis diaria por un mundo mejor para la humanidad, en estrecha unión con la naturaleza.

\section{Conclusiones}

Al finalizar el presente escrito, se obtienen algunas conclusiones, con la aclaración de que no son las únicas, pero que recogen la herencia de aquellos

\footnotetext{
37 Enrique Dussel, Hipótesis para el estudio de Latinoamérica en la historia universal, Red de Bibliotecas Virtuales de CLACSO,1966: 81, acceso: 31 de noviembre de 2020, http://bibliotecavirtual.clacso.org.ar/clacso/ otros/20120408102154/latino.pdf

38 Baraona, Diez ensayos..., 355-356.
} 
intelectuales que realizan un enorme esfuerzo por crear un pensamiento críticofilosófico genuinamente latinoamericano y caribeño. Se realizó, en este trabajo, un esfuerzo por rescatar los elementos fundamentales que, en la trayectoria histórica de los pueblos latinoamericanos y caribeños, han creado un escenario de dominación, dañando cultura e identidad dentro del ámbito de la modernidad y del desarrollo del sistema-mundo-capitalista. La interpretación temática sobre el humanismo latinoamericano y caribeño se realizó en dos fases que se concatenan para entender la evolución histórica de un pensamiento que se impregna de corrientes que reflejan implícita o explícitamente un pensamiento crítico-filosófico que nace de una realidad concreta latinoamericanista durante el siglo XX.

El trabajo se estructuró en una primera fase que comprende desde finales del siglo decimonónico hasta mediados del XX. Se concluye que durante este periodo histórico se concibió una teoría matizada con sentido crítico-filosófico, pero a su vez con una praxis transformadora de las realidades injustas de las sociedades del Continente. En esta acción teórico-práctica se empezó retomando el pensamiento martiano como un bastión para entender las realidades adversas que han tenido que enfrentar los pueblos de América; pero también, en este pensamiento la literatura y el arte han reafirmado las luchas liberadoras y emancipadoras como la independencia cubana o la revolución mexicana de 1910, así como los aportes de Siqueiros, Rivera y Orozco en la pintura muralista.

Esta primera fase sirvió para el análisis hasta aproximadamente mediados del siglo XX. El pensamiento crítico latinoamericano y caribeño propone alternativas sistémicas para luchar por las iniquidades, discriminaciones y opresiones que afectan a la mayoría de los pueblos. El mensaje y el discurso empleado por los representantes de este pensamiento crítico-filosófico de Nuestra América reflejan un profundo sentir humanista puesto que encierran una propuesta para la emancipación cultural y política donde medie un nuevo orden social.

En suma, surge una necesidad histórica para una Latinoamérica con identidad propia y no marcada por el dominador-colonizador que refleja una influencia determinante de la cultura eurocentrada. En el marco del pensamiento crítico, por supuesto, del cual han surgido debates sobre las posturas e interpretaciones entre algunos de sus representantes, pero sí se tiene claro que todos se han dirigido en una búsqueda por la dignidad y soberanía de los pueblos de América Latina que buscan reivindicaciones auténticas y apegadas a su cultura ancestral y en su identidad posterior a la llegada de los europeos al Continente. En esta fase, que culmina en la primera mitad del siglo XX, se destacaron José Martí, quien aunque es un representante del siglo XIX, su pensamiento se propagó en el siguiente siglo; José Enrique Rodó por el debate que creó su obra el Ariel; José Carlos Mariátegui por su visión marxista; José María Vasconcelos que planteó un nuevo humanismo y José María Gaos, cuyo aporte fue forjar la escuela hispanoamericana de filosofía.

En la segunda fase que se inicia a mediados del siglo $X X$, se refleja el fortalecimiento de un pensamiento humanista americanista que recoge lo mejor de ese ideario transformador de las realidades sociales y del ser humano. Se da 
una crítica al colonialismo, del cual surgen nuevas propuestas epistemológicas en el ámbito de la colonialidad, como, por ejemplo, Aníbal Quijano la colonialidad del poder; Walter Mignolo sobre la colonialidad del ser, saber y poder y Dussel que inyecta al pensamiento latinoamericano el componente de la universalidad de los seres humanos, como por ejemplo en Hipótesis para el estudio de Latinoamérica en la historia universal. Por otro lado, se dan los aportes en la creación de una historia de las ideas, de la filosofía, con el surgimiento de la Filosofía de la Liberación, la Teología de la Liberación y la Pedagogía del Oprimido, todas ellas permiten consolidar un movimiento liberador propio de Nuestra América. Finalmente se concluye que el pensamiento humanista latinoamericano y caribeño existe, está presente y se registra en los aportes teóricos de pensadores que representan el pensamiento crítico-filosófico de América Latina y del Caribe.

\section{Formato de citación según APA}

Calvo-Gómez, W. (2021). El humanismo latinoamericano y caribeño de la segunda mitad del siglo XX. Revista Espiga, 21 (42), páginas 71-98.

\section{Formato de citación según Chicago-Deusto}

Calvo-Gómez, Walter. «El humanismo latinoamericano y caribeño de la segunda mitad del siglo XX». Revista Espiga 21, n.o 42 (julio-diciembre, 2021):

páginas 71-98. 


\section{Referencias}

Ahumada Infante, Aldo. «La filosofía Nuestramericana en la filosofía chilena: una mirada a la segunda mitad del siglo XX». Intus-Legere Filosofía 6 (2), (2012), 50. Acceso: 3 de diciembre de 2020. http://www.academia.edu/ download/36563486/

DialnetLaFilosofiaNuestroamericanaEnLFilosofiaChilena-4510586.pdf

«La filosofía Nuestramericana en la filosofía chilena: una mirada a la segunda mitad del siglo XX». Intus-Legere Filosofía 6, n. 2 (2012): 4768. Acceso: 3 de diciembre de 2020, http://www.academia.edu/download/ 36563486/DialnetLaFilosofiaNuestroamericanaEnLFilosofiaChilena4510586.pdf

Altamirano Martínez, Héctor. «Notas sobre el pensamiento crítico latinoamericano y la construcción de democracias liberadora». Temas de Nuestra América. Revista de Estudios Latinoamericanos 34, 63 (2018): 4161. Acceso: 19 de diciembre de 2020. https://www.revistas.una.ac.cr/ index.php/tdna/article/view /10707

Arpini, Adriana. «Utopía y humanismo en el pensamiento latino americano: Eugenio María de Hostos y augusto Salazar Bondy». Revista Ágora, n.o 1920, Vol. X (2009): 25, acceso: 2 de marzo de 2021, http:// www.agoraphilosophica.com/Agora19-20/agora19-20-arpini.pdf

Baraona Cockerell, Miguel. Diez ensayos críticos. San José: Editorial Germinal, 2011.

Beorlegui Rodríguez, Carlos. Historia del pensamiento filosófico latinoamericano. Una búsqueda incesante de la identidad. Bilbao: Publicaciones de la Universidad de Deusto, 2010. Acceso: 25 de noviembre de 2020. https:// filosofiaum.files.wordpress.com/2014/06/beorlegui.pdf

Cerutti Guldberg, Horacio, Carmen Elena Villacorta, Carlos Pacheco Asselborn y Gustavo Óscar Cruz. «Filosofar desde sujetos y procesos liberadores de Nuestra América». En: Estudios latinoamericanos: diálogos interdisciplinarios sobre sociedad, historia, cultura, Frontera y territorio de María Laura Gili y Graciana Pérez Zavala. 1ạ ed. (Buenos Aires: Aspha, 2015), 107-125. Acceso: 28 noviembre de 2020. https:// www.academia.edu/37170559/Cap_Sujetos

Dussel, Enrique, Eduardo Mendieta y Carmen Bohórquez, Editores. El pensamiento filosófico latinoamericano, del Caribe $y$ «latino» (1300-2000): historia, corrientes, temas y filósofos. Ciudad de México: Siglo XXI Editores, 2009. 
Dussel, Enrique. Hipótesis para el estudio de Latinoamérica en la historia universal. Chaco: CLACSO, 1966. Acceso: 31 de noviembre de 2020. http:// bibliotecavirtual.clacso.org.ar/clacso/otros/20120408102154/latino.pdf

Fannon, Franz. Los condenados de la Tierra. Traducción de Julieta Campos. México: Fondo de Cultura Económica, 1972.

Fernández Nadal, Estela. «El humanismo latinoamericanista de Arturo Andrés Roig». Utopía y Praxis Latinoamericana 17, n.으 59 (2012): 11-26. Acceso: 17 de noviembre, 2020. https://www.redalyc.org/articulo.oa? id $=27925537008$

Fernández Retamar, Roberto. Pensamiento de nuestra América. Autorreflexiones y propuestas. Buenos Aires: CLACSO, 2006. Acceso: 2 de diciembre de $2020 . \quad$ http://biblioteca.clacso.edu.ar/clacso/formacion-virtual/ 20100721121022/retamar.pdf

Gómez Sánchez, Diana Marcela, Juan Guillermo Delgado Martínez y Néstor Iván Mejía Hincapié. «Aportes del pensamiento latinoamericano a la comprensión de la relación entre los conceptos de universidad, humanismo y sociedad». Revista Latinoamericana de Estudios Educativos 11, n. ${ }^{\circ}$ (2015): 69-91. Acceso: 20 de noviembre de 2020. https:// www.redalyc.org/articulo.oa?id $=134146842004$

Guadarrama González, Pablo. «Humanismo y autenticidad cultural en el pensamiento latinoamericano». Anales del Seminario de Historia de la Filosofía (2004):170. Acceso: 19 de noviembre de 2020. https:// dialnet.unirioja.es/servlet/articulo?codigo $=989377$

Guadarrama González, Pablo. «Hostos y el positivismo sui generis latinoamericano». Revista Historia de la Educación Latinoamericana 6, n.o 6, 209-234, (2004): 212. Acceso: 15 de diciembre de 2020. https:// www.redalyc.org/articulo.oa?id $=86900612$

Revisar. Hostos, Eugenio María de y Augusto Salazar Bondy», Revista Ágora 10, n. ${ }^{19-20}$ (2009): 8-34. Acceso: 2 de marzo de 2021, http:// www.agoraphilosophica.com/Agora19-20/agora19-20-arpini.pdf

Jenkins, Ryan. «Ariel y Calibán; Rodó y Martí». Gaceta Hispánica de Madrid (2006): 1. Acceso: 25 de noviembre de 2020. http:// www.gacetahispanica.com

Hinkelammert, Franz. Pensamiento crítico y crítica de la razón mítica. San José: CLACSO, 2007. Acceso: 21 de noviembre de 2020. http:// bibliotecavirtual.clacso.org.ar/Costa_Rica/dei/20120706111924/ pensamiento.pdf 
Martí, José. Selección y notas de Alfonso Chase y Dennis Mesén; pról. de Roberto Fernández Retamar. San José: Ministerio de Cultura, Juventud y Deportes, Departamento de Publicaciones, 1976: 554.

Magallón Anaya, Mario. «Filosofía y pensamiento crítico latinoamericano de la actualidad». Raíz Diversa. Revista Especializada en Estudios Latinoamericanos 1, n.o 1 (2014): 41-65. Acceso: 5 de diciembre de 2020. http://biblioteca.clacso.edu.ar/Mexico/ppel-unam/20160614015135/ Magallon.pdf

Maldonado Torres, Nelson. «La colonialidad del ser: contribuciones al desarrollo de un concepto». En Santiago Castro-Gómez y Ramón Grosfoguel. El giro decolonial. Reflexiones para una diversidad epistémica más allá del capitalismo global. Bogotá: Universidad Javeriana-Instituto Pensar, Universidad Central IESCO, Siglo del Hombre, 2007. Acceso: 25 de noviembre de 2020. http://www.unsa.edu.ar/histocat/hamoderna/ grosfoguelcastrogomez.pdf

Ribeiro, Darcy. Las Américas y la civilización. Proceso de formación y causas del desarrollo desigual de los pueblos americanos. México: Siglo XXI, 1971.

Roig, Arturo Andrés. La Historia de las ideas, teoría del discurso y pensamiento latinoamericano. Bogotá: Universidad de Santo Tomás, 1993. Acceso: 30 de noviembre de 2020. https://unamiradafilosofica.files.wordpress.com/ 2013/07/roig-1993.pdf

Quijano Obregón, Aníbal. Colonialidad del poder y clasificación social. Buenos Aires: CLACSO, 2014. Acceso: 1 de diciembre de 2020. http:// biblioteca.clacso.edu.ar/clacso/se/20140506032333/eje1-7.pdf

Salazar Bondy, Augusto. «Bartolomé o de la Dominación». En: Dominación y liberación. Escritos 1966-1974. Edición de Helen Orvig y David Sobrevilla. Lima: Fondo Editorial de la Facultad de Letras y Ciencias Humanas, Universidad Nacional Mayor de San Marcos, 1995.

Saladino García, Alberto. «El latinoamericanismo de José Martí». Latinoamérica. Revista de estudios latinoamericanos, n. ${ }^{\circ} 41$ (2005): 149-167. Acceso: 23 de noviembre de $2020 . \quad$ http://www.scielo.org.mx/scielo.php? script=sci_arttext\&pid=S1665-

$85742005000200149 \& \operatorname{lng}=\mathrm{es} \& \operatorname{tlng}=\mathrm{es}$

Scannone, Juan Carlos. «La filosofía de la liberación: historia, características, vigencia actual». Teología y vida 50, n. ${ }^{\circ} 1-2$ (2009): 56-73. Acceso: 27 de noviembre de 2020. https://scielo.conicyt.cl/pdf/tv/v50n1-2/art06.pdf

Velasco Gómez, Ambrosio. Humanismo. Ciudad de México: Universidad Nacional Autónoma de México, Instituto de Investigaciones Sociales (2009). Acceso: 28 de noviembre de 2020. http://conceptos.sociales.unam.mx/ conceptos_final/437trabajo.pdf 
Wallerstein, Immanuel. El capitalismo histórico. Madrid: Siglo XXI de España editores, 1988.

Walsh, Katherine. «Lo pedagógico y lo decolonial: Entretejiendo caminos». En: Pedagogías decoloniales: Prácticas insurgentes de resistir, (re)existir y (re)vivir. Tomo I, 1a Ed. Quito: Ediciones Abya-Yala 2013. Acceso: 2 de diciembre de 2020. http://agoradeeducacion.com/doc/wp-content/uploads/ 2017/09/Walsh-2013-Pedagog\%C3\%ADas-Decoloniales.Pr\%C3\%Alcticas.pdf 